\title{
"Peut-on Être Libanais et Brésilien?": La desaparición de los inmigrantes otomanos y la negociación de la identidad nacional y ciudadanía brasileña en Siria y el Líbano durante los años $30 \mathrm{~s}^{1}$
}

\author{
José D. Najar ${ }^{2}$
}

Recibido: 11 de agosto de 2019 / Aceptado: 1 de enero de 2020

Resumen. El objetivo de este trabajo es el de explorar el proceso circular de inmigración de los antiguos inmigrantes otomanos a Brasil y mostrar cómo su categorización como blancos, en su nueva patria, les ayudó a redefinir su sentido de ciudadanía en Brasil y en el Levante. En la década de 1930, cuando los burócratas del estado desistieron del sueño largamente esperado de una raza blanca brasileña, nuevas ideas sobre raza, color y etnicidad sostuvieron un discurso nacional emergente: Democracia Racial. Durante esta redefinición de raza/color, los antiguos inmigrantes otomanos, indiferentemente de su fe, negociaron constantemente su condición de inmigrantes blancos. Para miembros comunitarios, de toda religión, la negociación de su estatus en nación brasileña era una tarea transnacional. Durante los años 30s del mandato francés en Siria y el Líbano, brasileños naturalizados y sus descendientes no sólo reafirmaron su brasilidade, sino que continuaron identificándose como blancos. La idea de una "doble ciudadanía", brasileña y libanesa o siria, abrió un debate donde los ciudadanos brasileños tuvieron que confrontar el poder de los diferentes estados, que conjuntamente promulgaron leyes para producir ciudadanos leales a una sola nación. En resumen, los antiguos súbditos otomanos han sido centrales en la construcción de la raza y la ciudadanía al difuminar las líneas/fronteras encontradas a nivel mundial. Palabras clave: Inmigración otomana; doble ciudadanía; blancura; Brasil; siglo XX.

\section{[en] "Peut-on Etre Libanais et Brésilien?": The Disappearance of Ottoman Immigrants and the Negotiation of National Identity and Brazilian Citizenship in Syria and Lebanon in the 1930s}

\footnotetext{
Abstract. The objective of this work is to explore the circular immigration process of the old Ottoman immigrants to Brazil and to illustrate how their classification as whites in their new homeland helped them to redefine their sense of citizenship in Brazil and the Levant. In the 1930s, when state bureaucrats abandoned the long-awaited dream of a white Brazilian race, new ideas about race, color and ethnicity propped up an emergent national discourse: Racial Democracy. In this redefinition of race and color, the old groups of Ottoman immigrants constantly negotiated their condition as white immigrants, regardless of their faith. For the members of their community, of all religions, the negotiation of their status in Brazil was a transnational undertaking. During the 1930s in the French Mandate in Syria and Lebanon, naturalized Brazilians and their descendants not only reaffirmed their brasilidade; they also continued to identify themselves as white. The idea of a "dual nationality", Brazilian and Lebanese or Syrian,

1 Este trabajo es resultado de mi exposición en el panel organizado por Chiara Pagnotta titulado "Inmigración, Estado-Nación y "raza". Fronteras étnicas, políticas y culturales en América latina (XIX-XX siglos)" en la conferencia internacional de Latin American Studies Association 2018.

2 Departamento de Historia, Southern Illinois University, Carbondale (SIUC).

E-mail: jnajar@siu.edu
} 
opened a debate in which the Brazilian citizens had to confront the power of different states that were concurrently enacting laws that secured their citizens' loyalty to a sole nation. In summary, by blurring the lines/frontiers at a global level, the old Ottoman subjects were key figures in the construction of concepts of race and citizenship.

Keywords: Ottoman immigration; Dual Citizenship; Whiteness; Brazil; $20^{\text {th }}$ Century.

Sumario. 1. Introducción: Bienvenidos indeseables. 2. De inmigrantes a ciudadanos. 3. Asentamiento en São Paulo. 4. La ciudadanía blanca en Oriente Medio. 5. "Peut-on Être Libanais et Brésilien?". 6. Conclusión. 7. Referencias bibliográficas.

Cómo citar: Najar, J. D. (2020) "Peut-on Être Libanais et Brésilien?": La desaparición de los inmigrantes otomanos y la negociación de la identidad nacional y ciudadanía brasileña en Siria y el Líbano durante los años 30s, en Revista Complutense de Historia de América 46, 41-64.

\section{Introducción: Bienvenidos indeseables}

El 25 de junio de 1889, el Ministro de Agricultura de Brasil, el señor Lourenço Cavalcanti de Albuquerque, presidiendo la Sociedad Central de Inmigración reiteraba la importancia de algunas propuestas anteriormente hechas al gobierno imperial para impedir el embarque de súbditos otomanos (árabes y maronitas) en navíos anclados en puertos europeos con dirección a Brasil ${ }^{3}$. Con la esperanza de introducir el tipo de políticas de inmigración vigentes en los Estados Unidos, como la Ley de Exclusión de Chinos ${ }^{4}$ y el Proyecto de Ley de Justin S. Morrill (S. 141, 1887) , el ministro apoyaba la implementación de medidas legales preventivas aplicadas a los puertos europeos para evitar la amenaza de "elementos étnicos indeseables" contra Brasil, su gente y su civilización ${ }^{6}$. El gobierno imperial, tal vez adhiriéndose a los principios del contrato internacional de Amistad y Comercio con el Imperio Otomano, simplemente continuó reforzando las leyes que exigían pasaportes oficiales y visas brasileñas para los súbditos otomanos que ingresaran a Brasil.

A finales del siglo diecinueve, algunos meses antes de el derrocamiento de la monarquía brasileña en noviembre de 1889, una ola anti-otomana surgía de entre los debates públicos y de instituciones gubernamentales intentando evitar la entrada de inmigrantes del Imperio Otomano. La propuesta de prohibir la entrada a súbditos otomanos coincidió con los intentos del gobierno monárquico brasileño, y sus estados, para atraer inmigrantes europeos que sustituyeran la mano de obra esclava manumisa en $1888^{8}$. Esta aparente contradicción de esfuerzos desapareció de los debates públicos tras la proclamación de la Primera República Brasileña en noviembre 15, 1889, la cual otorgó la ciudadanía brasileña a toda persona residente en Brasil antes de esa fecha de acuerdo con el decreto de ley $\mathrm{n}^{\circ}$ 54-A del 14 de diciembre de 1889 sin importar raza, religión, o lugar de procedencia ${ }^{9}$. Al mismo tiempo que ley de ciudadanía

Gazeta de Noticias (RJ), nº 207, 26-VII-1889, 1.

Soennichsen, 2011; Railton, 2013; Lew-Williams, 2018.

Morrill, 1887.

Gazeta de Notícias (RJ), nº 207, 26-VII-1889, 1.

Sochaczewski, 2017: 193.

Skidmore, 1993: 128-144; Andrews, 1991: 54-89.

Brasil, 1891: 47. 
se promovía, el gobierno provisorio también instituyó una ley racista de emigración la cual excluía la entrada de asiáticos y africanos salvo con la autorización del congreso nacional ${ }^{10}$. Este aparente enigma, de una aceptación democrática de ciudadanía general y el establecimiento de leyes racistas, coincidía plenamente con la lógica discriminatoria del estado positivista. David Scott FitzGerald y David Cook-Martín han argumentado que la ideología liberal o democrática promovió una política migratoria racista desde el siglo diecinueve la cual dio preferencia a inmigrantes blancos europeos en América Latina ${ }^{11}$. Partiendo de este punto, este artículo discute como la clasificación racial blanca brindada a los inmigrantes otomanos desde su llegada a Brasil, por el estado brasileño, influyó en la negoción de su identidad nacional en la década de los años 1930s, especialmente cuando muchos de ellos regresaban temporalmente al Líbano y Siria, en aquel entonces bajo el mandato francés. Este trabajo hace uso de escasos periódicos que reportaron a fondo el tema de la inmigración otomana para Brasil y de la correspondencia diplomática encontrada en el Archivo del Ministerio de las Relaciones Exteriores (Itamaraty), en Río de Janeiro, que alberga cartas, telegramas, artículos de periódicos, y todo tipo de trámites efectuados a cada día en la embajada brasileña en la ciudad de Beirut, hoy Líbano. Dado la riqueza de estas fuentes, podemos analizar de manera sistemática, más allá de las historias memoriales, la cuestión y elementos de la ciudadanía brasileña, especialmente en Siria y Líbano bajo el control francés. Es importante resaltar que este fue un periodo histórico donde la lógica del estado-nación, y hasta el mismo neocolonialismo, forzó al conjunto de estados a trabajar colectivamente para anular la idea fugaz de una doble ciudadanía al imponer leyes nacionales, locales, e inter y transnacionales específicamente diseñadas para reforzar los límites de una única ciudadanía nacional. Un proceso que afectó directamente la vida de hombres, mujeres y niños, quienes, en algún momento, aprendieron a lidiar con la realidad de este nuevo orden mundial.

El 23 de julio de 1889, el navío transatlántico francés, Béarn, llegó al puerto de Río de Janeiro transportando a 900 pasajeros, entre ellos 270 súbditos otomanos acompañados por dos sacerdotes ${ }^{12}$. A su llegada a Río de Janeiro, el capitán Lyrio Vert recibió una orden del Ministro de Agricultura, el señor De Albuquerque, en la cual el ministro negó la entrada a todos los súbditos otomanos a bordo de su barco. Obedeciendo esa orden, el capitán después de un día anclado en el puerto de Río, continuó su viaje a la ciudad de Montevideo, Uruguay. A medida que la nave reiniciaba su viaje con destino al Uruguay, los súbditos otomanos a bordo se amotinaron. No dispuestos a aceptar la decisión tomada por las autoridades brasileñas, quienes le negaron la entrada al país, cuatro de los pasajeros "se lanzaron al mar"13. Las rápidas acciones tomadas por un guardia de aduanas y un tripulante de un barco de pesca, que pasaba por allí, salvaron a los cuatro hombres que fueron devueltos al Béarne. El Capitán Vert regresó al puerto carioca y solicitó la ayuda de las autoridades para controlar a la multitud enfurecida. Los hombres rescatados expresaron a las autoridades su voluntad de perecer antes que continuar su viaje a Montevideo. Los individuos explicaron que, entre sus compañeros, todos en conjunto habían traído consigo mercancías con el valor de treinta contos de reis, artículos todavía en posesión de la ofi-

\footnotetext{
Skidmore, 1993: 137; Andrews, 1991: 52.

FitzGerald - Cook-Martín, 2014: 2.

Gazeta de Notícias (RJ), nº 208, 27-VII-1889, 2.

Ibídem.
} 
cina carioca de aduanas. El encontrarse sin sus pertenencias materiales fue la razón principal por la cual los amotinados se negaban a navegar a Montevideo. Seducidos por las promesas de una nueva vida hecha por los sacerdotes que los acompañaban, y que ya habían desembarcado, los viajeros habían vendido tierras y propiedades en sus pueblos de origen para pagar su viaje y rehacer sus vidas en Brasil ${ }^{14}$.

Percibiendo altos niveles de ansiedad a bordo, el Capitán Vert cedió el control de su navío al Primer Teniente Alberto Corrêa de Matos, en cuanto él llegaba a tierra firme para pedirle a las autoridades competentes soluciones que garantizarán no solo su seguridad, sino también la seguridad de los pasajeros de primera y segunda clase en caso de que la insurrección reiniciase durante el viaje a Montevideo. El jefe de la policía al no poder proporcionarle ayuda, lo dirigió al Ministro de Justicia, el señor Candido de Oliveira, que de la misma manera no lo pudo ayudar. La única ayuda que le proporcionó fue el envío de miembros de la fuerza policial para desarmar al grupo de otomanos a bordo del barco, los cuales supuestamente tenían en su poder cuchillos y pistolas. Además, el Inspector Jefe de Aduanas ordenó a veinte marineros imperiales armados que vigilaran el barco durante la noche e instruyó al Sargento Leoppoldino de Mendoça para que protegiera la bahía en general. El buque Riachelo se mantuvo alerta en caso de que el Béarn necesitara ayuda. A las once de la noche, los esfuerzos de todos los involucrados habían finalmente restablecido el orden a bordo de la nave francesa ${ }^{15}$.

Durante las siguientes ocho horas, todas las ramas del gobierno, incluido el Ministerio de Agricultura y el Ministerio de Justicia, trabajaron conjuntamente para resolver el destino de los pasajeros amotinados. Las autoridades resolvieron admitir al país únicamente a los otomanos que tuvieran consigo pasaportes con visas de las autoridades respectivas; estos eran una minoría de los otomanos ya que la mayoría no poseía tales documentos. El capitán, por su vez, imploró a las autoridades francesas, en Río, que aumentara el número de empleados a bordo del Béarn por temor a que los viajeros resentidos intentaran incendiar el barco, ya que muchos de ellos habían amenazado con hacerlo. El Capitán Vert fue muy firme en su deseo de proteger su nave, sus pasajeros y su tripulación hasta el punto de anclarse indefinidamente en Río de Janeiro hasta no recibir las garantías necesarias para protegerlos a todos ${ }^{16}$.

Este incidente fue utilizado por el señor de Albuquerque como ejemplo justificativo para subrayar la necesidad de instituir leyes que prohibieran la llegada de inmigrantes otomanos a territorio brasileño. En su reunión del 29 de julio con la Sociedad Central de Inmigración, además de reiterar la necesidad de una "medida simple" para evitar tales inconvenientes, el ministro insistió en que el gobierno debería multar a los capitanes que transportaran inmigrantes indeseables a Brasil, una práctica que, de acuerdo con el magistrado sin bases oficiales, era común en los Estados Unidos de Norte América. De Albuquerque señaló que en los EE.UU. los capitanes trasportando a tales indeseables eran multados entre 250 y 500 dólares por pasajero. El ministro explicó que, si ese tipo de leyes hubieran estado en vigencia en Brasil, el capitán del Béarn ya hubiera pagado una fuerte multa. Además, el capitán se habría

14 Existen varios trabajos sobre la emigración y de la memoria de la emigración siria y libanesa para Brasil, especialmente para el estado de Rio de Janeiro y São Paulo, véase algunos de ellos, Abdeluahed, 2009; Duoun, 1944; Gattaz, 2005; Greiber - Saigh - Cattini, 1998; Hajjar, 1985; Khatlab, 1999; Osman, 2011; Pinto, 2010; Sáfady, 1972.

15 Gazeta de Notícias (RJ), nº 208, 27-VII-1889, 2.

16 Gazeta de Notícias (RJ), no 209, 28-VII-1889, 1. 
visto obligado a llevarse con él a todos los pasajeros que trataron de desembarcar en los puertos brasileños sin pasaportes adecuados ${ }^{17}$.

El 30 de julio por la tarde el embajador francés, Henri de Lavaur de Saint-Fortunade, y un representante de la compañía de la línea transatlántica de Marsella, Messageries Martitimes, abordaron el Béarn. Una vez en el barco, el embajador se reunió con los pasajeros otomanos que habían viajado a Río sin documentos oficiales. Los pasajeros explicaron que ellos eran en su mayoría cristianos católicos del Líbano. Entre ellos había sastres, herreros, carpinteros y agricultores. Algunos de ellos ya eran residentes en Brasil, donde vivían con sus familias ${ }^{18}$. Uno de los hombres le dijo al embajador francés que encomendado por su hermano, un agricultor de la ciudad de Campos, fue al Líbano a buscar trabajadores para emplearlos en las fincas pertenecientes a su hermano. Ya de regreso, cumpliendo los deseos de su hermano, se encontraba con leyes cuáles él desconocía que prohibían la entrada de súbditos otomanos en Brasil. Al día siguiente, el 31 de agosto, el jefe de policía abordó el barco y, después de revisar los documentos de los 270 súbditos otomanos, permitió que solo quince desembarcaran, ya que sus documentos estaban en regla ${ }^{19}$. Las medidas inquebrantables seguidas por las autoridades brasileñas y aplicadas al grupo de otomanos tal vez influyeron en el rechazo, por parte del barón de Miranda, de una solicitud presentada por varios hacendados de la ciudad de Campos, Rio de Janeiro, para admitir a unos 12,000 "chin" y "culis" [sic] para trabajar en sus tierras ${ }^{20}$. La Sociedad Central de Inmigración aplaudió el rechazo de los trabajadores asiáticos mientras celebraban la intervención de las autoridades contra aquellos que no tienen una "orientación adecuada sobre las cosas" y quienes en un momento de dificultad personal intentaron "comprometer el futuro de una gran nación" 21 . Además, La Sociedad Central de Inmigración informó que la República Argentina había cerrado sus puertos a todos los súbditos otomanos, una medida que la Sociedad confirmó como prueba del "cuidado que se debe tener al recibir elementos étnicos dañinos"22.

Sin embargo, la celebración de la Sociedad Central de Inmigración repentinamente cambio de júbilo a desilusión por las acciones tomadas por el señor Arthur Macedo, un oficial de la Policía Portuaria. El 1 de agosto, alrededor de las 5 p.m., el señor Macedo en compañía del Inspector Jefe de Aduanas, permitió que todos los inmigrantes otomanos aun abordo, y sin los documentos apropiados, que desembarcaran del Béarn, habiendo presentado sus "herramientas de trabajo" como prueba de que serían útiles para el país ${ }^{23}$. La compañía Messageries Maritimes ayudó con el traslado de los pasajeros a tierra contra las órdenes directas del gobierno brasileño, según informes de la prensa ${ }^{24}$. La Gazeta de Notícias, en Río de Janeiro, informó que los turcos involucrados en la revuelta a bordo del Béarn, "finalmente lograron lo que deseaban-desembarcar". El artículo culpaba a las "vacilaciones e incertidumbres" de los funcionarios brasileños hacia la "tenacidad y resistencia" de los alborotado-

\footnotetext{
Gazeta de Notícias (RJ), nº 211, 30-VII-1889, 1.

Gazeta de Noticias (RJ), nº 212, 31-VII-1889, 1.

Gazeta de Noticias (RJ), nº 213, 1-VIII-1889, 1.

Gazeta de Noticias (RJ), nº 215, 3-VIII-1889, 1.

Ibídem.

Ibídem.

Ibídem.

Gazeta de Notícias (RJ), n² 215, 3-VIII-1889, 1.
} 
res $^{25}$. También, presentaba a las mujeres turcas como máquinas reproductoras de bebés, las cuales pronto aumentarían rápidamente la cantidad de otomanos en todo Brasil. "Esta fue una colonización de ojos hermosos, un comercio de cruces de marfil, una industria de cuentas de vidrio, rosas de Jericó y niños muy sucios", reportaba el diario, "perfectamente versados en el arte de la mendicidad: esto es lo que vomitó el Béarn nuestra tierra e impidió continuar su ruta" ${ }^{26}$. Como una crítica más amplia al gobierno, el artículo atacaba la incapacidad del gobierno brasileño para suministrar con agua a los sectores circundantes de Río de Janeiro. El artículo concluyó notando que, aunque la "invasión de los hijos de Mohamed" no fue una invasión peligrosa, los inmigrantes otomanos ofrecieron "en el capítulo de las costumbres" lo peor: el juramento de nunca bañarse ${ }^{27}$. Quizás al permitir la colonización de la provincia por parte de los hijos del Imperio Otomano, el gobierno brasileño no tendría que invertir en infraestructura para satisfacer la necesidad de agua en la ciudad.

Posteriormente, el oficial Arthur Macedo enfrentó las represalias del jefe de policía, que citando el art. 26 del Reglamento no 1746 de abril 16 de 1856, suspendió a Macedo por treinta días acusándolo de desobedecer deliberadamente las órdenes oficiales relacionadas con el desembarque de pasajeros otomanos ${ }^{28}$. Durante las siguientes dos semanas, la Sociedad Central de Inmigración notificó a las autoridades que todos los súbditos otomanos desembarcados "llegaron por su propia cuenta y no recibieron asistencia del gobierno", un hecho que tranquilizó, al menos por algunos días, a varios miembros del gobierno brasileño, entre otros sectores de la sociedad brasileña ${ }^{29}$. Sin embargo, el sentimiento de una amenaza invocada por los viajeros, inmigrantes y residentes otomanos no desapareció. La Gazeta informó que más de 500 pasajeros otomanos se dirigían a Brasil a bordo del próximo barco francés ${ }^{30}$. Sin embargo, esta fue la última vez que los diarios comentaron sobre los inmigrantes otomanos. Quizás la creciente inestabilidad política causo el fin de los ataques a la inmigración otomana.

\section{De inmigrantes a ciudadanos}

E1 26 de noviembre de 1889, el gobierno provisional brasileño promulgó el decreto n. ${ }^{\circ} 13-\mathrm{A}^{31}$. El decreto otorgó la ciudadanía a todos los extranjeros que desearan convertirse en ciudadanos brasileños naturalizados. Un mes después del anuncio, una enmienda a la ley por el decreto n. ${ }^{\circ}$ 54-A del 14 de diciembre, revisó el proceso de naturalización. En lugar de permitir que las personas solicitaran la naturalización, el decreto n. . $^{54-A}$ consideró como ciudadanos brasileños "todos los extranjeros que ya residían en Brasil el 15 de noviembre de 1889"32. La ley revisada otorgaba a todos los ciudadanos naturalizados "todos los derechos civiles y políticos" de que disfrutan los brasileños nacidos en el país, con la excepción de ocupar el cargo de presidente

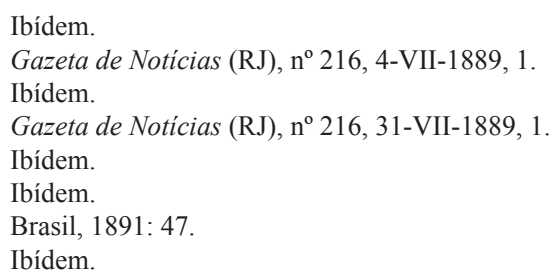


de la república. Además, el decreto . $^{\circ}$ 58-A estableció un período requerido de dos años de residencia para los futuros extranjeros que desearan convertirse en brasileños naturalizados. Los autores de la ley, sin embargo, no proporcionaron canales alternativos para rechazar la ciudadanía de facto. Este descuido forjó las bases del decreto n. ${ }^{\circ} 396$ del 15 de mayo de 1890. El nuevo decreto proporcionó a los residentes extranjeros las facultades para rechazar la ciudadanía brasileña mediante la firma de una declaración legal en oficinas locales del gobierno municipal, estaciones de policía, embajadas, o con un diplomático representando a su nación correspondien$t^{33}$. Los residentes extranjeros que desearon retener su ciudadanía extranjera fueron forzados a cumplir con la nueva ley en un plazo de seis meses, plazo que se extendió necesariamente hasta el 31 de diciembre de 1890.

Pero la "gran naturalización", como se le conoció, convertida entonces en ley nacional, no fue recibida abiertamente por algunos gobiernos europeos. El diario parisino, Le Brésil, reimprimió, el 7 de septiembre de 1890, parte de la respuesta oficial a las objeciones "idénticas" hechas por los gobiernos de Lisboa, Madrid, Roma, Londres y Viena, relacionadas con las nuevas leyes brasileñas de naturalización táci$\mathrm{ta}^{34}$. Estos regímenes europeos argumentaban que el decreto n. ${ }^{\circ}$ 54-A había impuesto a la libertad individual de estas personas una restricción inadmisible, en contra de los principios generalmente aceptados, y prejuicios contra los intereses de los extranjeros residentes en Brasil. La ley, en la opinión de esos países, carecía de fundamentos jurídicos. Como resultado, las naciones europeas solicitaron la anulación o al menos la modificación de la ley permitiendo que el extranjero la solicitara por su propia cuenta. De esta manera, aquellos que desearan convertirse en brasileños podrían hacerlo libremente; simultáneamente los que no solicitaran la naturalización conservarían la propia.

Sin embargo, el Ministro de Relaciones Exteriores de Brasil, el señor Quintino Antônio Ferreira de Sousa Bocaiuva, rechazó esa interpretación particular de la ley. En su respuesta oficial, el ministro alegó que el decreto relativo a la nacionalización de residentes extranjeros, que voluntariamente deseaban aceptarlo, buscaba reconciliar las "simpatías de la opinión pública en todos los países civilizados" en lugar de causar "preocupaciones o temores" con respecto a sus intereses. Esto se debió principalmente al doble alcance del propósito y los efectos del decreto. Señaló, el ministro, que el decreto otorgaba la ciudadanía brasileña a todos los extranjeros al mismo tiempo que establecía conductos para rechazarla. Por esta razón, el decreto no violaba ningún derecho personal. Por otro lado, el ministro les recordó a los gobiernos opositores que las leyes de "todos los países civilizados", en virtud de su soberanía, regulaban el proceso de naturalización y, por lo tanto, era un asunto nacional, no internacional. Subrayó que el "silencio", por parte de los residentes extranjeros era, de hecho, un acto de aceptación de la ciudadanía brasileña. Para apoyar esta práctica relativamente común, el ministro citó cuatro ejemplos diferentes de países que ejercían este patrón. Portugal, España, Italia e Inglaterra requerían que individuos,

\footnotetext{
Brasil, 1891: 48.

34 La correspondencia diplomática entre el Ministerio de Relaciones Exteriores de Río de Janeiro y las sedes diplomáticas en este artículo se encuentra en el Palácio Itamarity, Arquivo do Ministério das Relações Exteriores (en adelante PI-AMRE), presentada bajo la ciudad donde se estableció la embajada, en este caso por ejemplo Paris o Beirut, bajo su propio sistema de organización de documentos. Consul Monteiro al Ministro Bocaiuva. Brasil, 10-IX-1890. Palácio Itamarity, Arquivo do Ministério das Relações Exteriores [Francia] (en adelante PI-AMRE), 225/3/13. Doc. n. 13, anexo 2.
} 
con diferentes circunstancias al nacer y que deseaban reclamar la ciudadanía de esas naciones (es decir, hijos de padres extranjeros, niños nacidos en un país extranjero), cumplieran con la ley a través de declaraciones por escrito en las cuales declaran su deseo de ser reconocido como ciudadanos. En estos casos, el ministro notó que la acción de mantener el "silencio" de estos individuos "determinó su nacionalidad de forma obligatoria" 35 . La maniobra táctica de Bocaiuva entre las leyes nacionales e internacionales, basada en la precedencia europea, finalmente resultó en la implementación incuestionable de la gran naturalización.

La victoria de las nuevas leyes de ciudadanía, en Brasil, significó que todos los extranjeros tuvieron, una vez más, que tomar otra decisión que les cambiaría la vida: permanecer permanentemente en su país anfitrión como ciudadanos brasileños. Esto no obstaculizó a la Sublime Porte (el gobierno otomano), a través de su embajada en París, en su continuo desafío a la legitimidad de las leyes brasileñas, o cualquier ley fuera del ámbito de las prácticas legales otomanas ${ }^{36}$. Sin embargo, durante el período provisional para rechazar la ciudadanía, en la ciudad de São Paulo, sólo treinta hombres mantuvieron su lealtad al sultán otomano ${ }^{37}$. No está claro si los treinta otomanos eran jefes de hogar, hombres solteros o casados que vivían solos en Brasil, o una combinación de ambos. Los registros oficiales identificaron la nacionalidad del grupo como turcos y no como sirios o árabes, como han sugerido otras fuentes oficiales, como registros diplomáticos o de inmigración. Los que se mantuvieron leales al Sultán, como Felipe Arabe, Miguel Curi y Ubebe Salim, declararon ser vendedores ambulantes, al igual que la mayoría de los otros treinta hombres. Solo cuatro de ellos, como Felippo Sebastião y Miguel Estefano, se identificaron como hombres de negocios. Furlani Sarcio, simplemente se identificó como un trabajador ${ }^{38}$. La elección personal hecha por cientos, si no miles de súbditos otomanos, para permanecer en Brasil, cambió drásticamente la dirección en la que mirarían hacia el futuro. Como resultado de su nueva realidad como ciudadanos brasileños, los antiguos inmigrantes otomanos comenzaron a construir una comunidad para salvaguardar su interés social, económico y político en un país en el que se habían hecho iguales, a los ojos de la ley, a sus nativos contrapartes, mientras mantenían lazos estrechos con las tierras que los vieron nacer.

\section{Asentamiento en São Paulo}

En 1898, el número de inmigrantes otomanos que practicaban la fe maronita era lo suficientemente significativa en São Paulo que la comunidad construyó la primera iglesia de rito maronita en la ciudad de Campinas el 3 de marzo de ese año ${ }^{39}$. El periódico, O Debate, reportó el evento como "una ceremonia para la colocación de la primera piedra y la bendición del sitio" 40 . Después de la ceremonia religiosa,

\footnotetext{
35 Ibídem.

36 El Imperio Otomano históricamente desenvolvió sus prácticas diplomáticas diferentemente que los países europeos, véase Berridge, 2004; Kircuoglu, 2004; Kutlu, 2012; Lewis, 2004.

37 Recusaram a cidadania brasileira. Brasil, 1890. Acervo Municipal de São Paulo [AMSP], Fundo: CMSP/ INTDM/PMSD, Serie: Assumptos Diversos, Datas 1538-1955, 44-135 [en adelante AMSP-C/I/P-AD].

38 Recusaram a cidadania brasileira. Brasil, 1890. AMSP-C/I/P-AD, 45, 75, 135, 56, 96, 56.

39 O Debate (SP), no 153, 4-III-1898, 2. Veáse Truzzi, 2016: 266-291; Knowlton, 1955: 273-277.

40 O Debate (SP), n $153,4-$ III-1898, 2.
} 
Sheikh El-Kouri se dirigió a la audiencia en francés, hablando de la "persecución que sufrieron los cristianos en Palestina donde ninguno de sus derechos fue respetado, ni ellos tenía libertad debido a la política cruel y bárbara del sultán" ${ }^{41}$. Además, el artículo nombró a Francisco de Miranda como el filántropo que había donado la parcela de tierra utilizada para la construcción de la iglesia. En un país donde los cristianos otomanos pertenecían a la mayoría religiosa, y su integración a la sociedad paulista podía lograrse sin temor a políticas confesionales, la hermandad cristiana no garantizaba necesariamente la ausencia de conflictos sociales entre ellos o entre otras comunidades ${ }^{42}$.

Al representarse homogéneamente a sí mismos como cristianos y con su condición de blancos, en Brasil, los inmigrantes otomanos forjaron una noción de ciudadanía muy distinta a la de sus contrapartes no-blancos ${ }^{43}$. Esta forma de ciudadanía cristiana y blanca estaba en línea con los ideales de integración social entre las élites en América Latina. Sin embargo, esto no era simplemente una estrategia para la supervivencia de los inmigrantes otomanos, sino que esta era también una técnica para la movilidad social ${ }^{44}$. Mientras, todas las asociaciones de ayuda mutua y solidaridad promovían la idea de "seres humanos rigurosamente iguales" 45 y, en el contexto de su cultura material en la nueva tierra de oportunidad, estas relaciones eran viables en la "reproducción material de sus existencias" ${ }^{46}$. Por lo tanto, esta comprensión de sí mismos, cegó a esta comunidad a reconocer su papel en la perpetuación de las desigualdades raciales en su nueva patria ${ }^{47}$. Esta ciudadanía blanca y cristiana permitió que los inmigrantes otomanos hicieran realidad sus sueños de un futuro mejor a costa de la disparidad racial.

A medida que los inmigrantes otomanos, en São Paulo, comenzaron a labrarse un lugar en la sociedad brasileña, la elite adinerada adoptó la idea de fazer America, la versión brasileña del "sueño americano". El relativo éxito de los hombres de negocios inmigrantes de la élite otomana, en el creciente mercado capitalista, pronto colisionó con la idea de "fazer America" de miles de otros inmigrantes que buscan su propia fortuna, entre ellos los pobres inmigrantes otomanos. Sidney Chalhoub señala que "más de la mitad de los 89,000 extranjeros económicamente activos trabajaban en el comercio, la industria manufacturera y las actividades artísticas, la población inmigrante ocupaba las áreas más dinámicas del empleo"48. Dentro de este dinámico entorno económico, el "fazer America" de la élite inmigrante otomana se materializó en la movilidad económica, debido a su creciente monopolio de la industria de la confección de ropa en São Paulo. Sin embargo, es importante señalar que el éxito económico de los inmigrantes otomanos no solo provino de los negocios de prendas

\footnotetext{
41 Ibídem.

42 Domingues, 2004. Para estudios de inmigración europea a Brasil, véase Hutter, 1986; Fausto, 2000; Cortês, 1958; Hormeyer, 1986. Estudios referentes a los programas estatales para la inmigración europea, véase Conrad, 1986 y 1993 [1972]; Mendoça, 2001.

Fausto, 1984: 39.

43 Dávila, 2004: 111. En Estados Unidos, los sirio y libaneses acudieron a las cortes para exigir su clasificación de blanco que en torno los hacia elegibles para la ciudadanía americana, véase Gultieri, 2009; Lopez, 1996.

44 Los trabajos de Oswaldo Truzzi demuestran esta movilidad social en su profundidad, véase Truzzi, 1993, 1995, 1997 a y b, 2000.

45 O Debate (SP), n 153, 4-III-1898, 2.

46 Chalhoub, 2001: 132.

47 Bento, 2002: 25-58; Dávila, 2004: 111.

48 Chalhoub, 2001: 26.
} 
de vestir, sino también de la capacidad de los miembros para evaluar oportunidades comerciales utilizando su posición privilegiada como blancos la cual les daba acceso a esos campos económicos. En la historiografía se pueden encontrar un sin número de ejemplos de la movilidad social de esta comunidad que para los años 20 s, los súbditos otomanos hora se dividía entre sirio y libaneses ${ }^{49}$.

\section{La ciudadanía blanca en Oriente Medio}

Cuando el consulado brasileño en Beirut comenzó a implementar políticas nacionales e internacionales, así como servicios civiles, aplicables a sus ciudadanos que residían en la región del Levante, lo hizo mediante la reproducción de normas socioculturales naturalizadas dentro de sus estructuras de poder. Un elemento importante, aunque discreto, introducido en las funciones diarias del consulado fue el sistema de clasificación racial/color. La raza y/o el color se convirtieron en un marcador esencial en el proceso de identificación personal que definía en gran parte la ciudadanía de los brasileños. El sistema racial tenía raíz en las estructuras de las castas coloniales $^{50}$. Se había utilizado conceptualmente en Brasil desde el período colonial, pero se instituyó burocráticamente durante la Primera República ${ }^{51}$. En Brasil, la década de 1930 presenció un aparente cambio conceptual, o de reorientación, que transformó las categorías de raza y/o color entre algunos sectores de la población, en formulaciones étnica. El aumento de la etnicidad en las ciencias sociales, y círculos políticos, oscureció el continuo proceso de clasificación humana de acuerdo con la lógica positivista del color. La potencia y utilidad de la etnicidad para el estado brasileño yacía en el carácter indefinible del término mismo. En algunos casos, la etnicidad abarcaba diversos grupos religiosos, como la población judía. En el caso de las comunidades japonesa, siria-libanesa y coreana, las fronteras políticas de las naciones-estado modernas sirvieron para definir el carácter "étnico" de cada grupo. La etnicidad, como lo muestran Jeffrey Lesser y John T. Karam, fue una verdadera fuente de autoidentificación y un proceso de negociación con el estado ${ }^{52}$.

Sin embargo, para las comunidades sirio-libanesas de Brasil, la clasificación racial o de color no cambió con el tiempo. Los acalorados debates que estallaron en la década de 1930 sobre la conveniencia social y económica de los inmigrantes judíos y árabes en Brasil deben entenderse en el contexto de las políticas de inmigración durante la recesión económica mundial que se sumó al surgimiento de los movimientos nativistas nacionales que ampliaron las nociones de antisemitismo y sentimiento antiárabe. Gran parte del proceso de nacionalización étnica en Brasil, bajo el presidente Getúlio Vargas, fue negociado por grupos y organizaciones judías y árabes a medida que transformaron sus organizaciones étnicas en brasileñas más inclusivas. Esto fue porque en los ojos del Estado, existía una diferencia significativa entre las comunidades étnicas de la nación, que por ley gozaban de todos los privilegios garantizados por la constitución brasileña y de los elementos extranjeros que buscaban emigrar a Brasil.

49 Campos, 1987.

50 Por ejemplo, véase Earle, 2012; Loveman, 2014.

51 El sistema positivista de identificación personal, basado en la antropología criminal, surgió como parte del estado al principio de los 1900s; véase Camil, 1898.

52 Lesser, 1999: cap. 3; Karam, 2007: 3-6. 
En la perspectiva de las autoridades consulares brasileñas en Beirut, los brasileños de descendencia siria y libanesa fueron clasificaron como blancos y disfrutaron de todos los derechos y libertades de sus contrapartes en Brasil. El 17 de noviembre de 1933, el consulado brasileño en Beirut registró el primer nacimiento de un ciudadano brasileño en el área del Levante. Si bien este nacimiento no fue el primero en el Levante, fue el primer nacimiento registrado en el corto período de funcionamiento del nuevo consulado de carrera. En ese día, Zaki Namour, un brasileño naturalizado, llegó a Beirut con la intención de registrar a su hijo con las autoridades del consulado. Namour viajó desde la ciudad de Homs en Siria, donde vivía, en compañía de Jorge Camasmiyé y Aziz David Nabki, sus dos testigos. Los tres hombres, en presencia del cónsul brasileño, Mario da Costa, declararon que Julia Namour, la esposa, "había dado a luz el 2 de febrero de [ese año] a las siete de la mañana a un niño de sexo masculino y de color blanco, que recibió el nombre de Mario" ${ }^{53}$. El color blanco asignado a Mario en su certificado de nacimiento confirmó la visión estatal de los sirio-libaneses como ciudadanos blancos, incluso cuando la etnia suplantó a las categorías raciales en todo el estado brasileño. Este hecho se reflejó en los certificados de nacimiento de Roberto Khasba, Costantino Curie, Maire-Thérése Khasba, y Mouna y Rita Elias Issa ${ }^{54}$. Aunque estos niños nacieron en el Líbano o Siria y de padres sirios y/o libaneses, la ciudadanía política brasileña adquirida por sus padres a través del proceso de naturalización no solo aseguró su ciudadanía brasileña, sino también su color blanco en una sociedad estratificada por jerarquías de color. En términos más generales, hubo poca diferencia en la forma de articular la ciudadanía y el color entre los brasileños sirio-libaneses nacidos en Oriente Medio, donde el color se registró en los registros oficiales, de la misma manera que sus compatriotas nacidos en Brasil: todos los sirios y libaneses continuaron surgiendo en el lado blanco del espectro racial en ambos lados del Atlántico.

El 24 de abril de 1933, la embajada de Brasil en Beirut recibió una solicitud para la repatriación de cuatro ciudadanos brasileños. Esta solicitud, a diferencia de muchas otras procesadas por la embajada, llamó la atención de los funcionarios brasileños ya que el remitente era el respetable abogado, Michel Boulos, de la ciudad de Tartus, Siria. En su carta, Boulos rogó a los funcionarios brasileños que ayudaran a un grupo de cuatro hermanos y hermanas que vivían en condiciones "miserables" a ser repatriados a su tierra natal, Brasil ${ }^{55}$. La familia del joven Mamed Ali estaba compuesta por dos niñas, Vedalice, de 13 años, y Olinda, de 10 y dos niños, Mamed, de 17 años, y Miguel, de 14 años. Mientras gestionaba el caso en nombre de los cuatro niños, Boulos explicó brevemente las condiciones bajo las cuales los menores se encontraban. Los cuatro niños habían partido de Brasil en compañía de su padre, Abdalla Haje Ali, bajo el pretexto de que, en este viaje

53 Registo Civil em 1933. Brasil, 10-II-1934. PI-AMRE. Beirut. CB 54/5/15. Oficio 12, Anexo 1.

54 Roberto Khasba nació el 14 de septiembre de 1934 (Registo Civil em 1935. Brasil, 14-I-1936. PI-AMRE. Beirut. CB 54/5/15. Oficio 8, Anexo 1; Constantino Curie el 4 de enero de 1936 (Registo Civil em 1937. Brasil, 26-II-1937. PI-AMRE. Beirut. CB 54/5/15. Oficio 13, Anexo 1); Maire-Thérése Khasba el 10 de mayo de 1938 (Registo Civil em 1939. Brasil, 25-I-1939. PI-AMRE. Beirut. CB 54/5/15. Oficio 8, Anexo 1); Mouna and Rita Elias Issa nacio el 21 de Agosto de 1938 (Registo Civil em 1939. Brasil, 25-I-1938. PI-AMRE. Beirut. CB 54/5/15. Oficio 6, Anexo 2); por error a Rita Elias Issa se le registró la fecha de nacimiento como el día 14 de septiembre de 1938 (Registo Civil. Brasil, 125-I-1938. PI-AMRE. Beirut. CB 54/5/15. Oficio 8, Anexo 3), este error fue corregido y su fecha de nacimiento reflejo el año correcto de 1938 (Registo Civil. Brasil, 9-VI-1939. PI-AMRE. Beirut. CB 54/5/15. Oficio 54, 10).

55 Repatriação de mamede Ally Jr. e Irmãos. Brasil, 9-VIII-1933. PI-AMRE. Beirut. CB 54/5/15. Oficio 38, Anexo 1. 
de regreso a su tierra natal, el padre liquidaría todas sus posesiones materiales. El señor Ali dejó a su esposa y su hijo menor, aún de pecho, en Brasil como garantía de su regreso. Sin embargo, una vez en Tartus, Ali cambió de opinión y poco después de su llegada, "se casó con una mujer musulmana y trató de casar a sus hijas, a pesar de sus cortas edades, con el objetivo de obtener un gran premio: este es la venta [de sus hijas]"56. Para Boulos, esta tradición islámica contradecía sus valores occidentales y religiosos que posiblemente, en algún nivel, esperaba también tocara el lado sensible de los empleados de la embajada. Boulos terminó su carta señalando que ninguno de los hijos de Ali deseaba quedarse en Siria y que "estaban decididos a regresar a su país natal" ${ }^{57}$. Boulus añadió que el señor Ali se oponía a la repatriación de sus hijos porque carecía de fondos monetarios para pagar los boletos de regreso. Estas deplorables circunstancias habían llevado a los hijos de Ali a buscar la ayuda de Boulus.

Unas semanas más tarde, Boulus volvió a comunicarse con la embajada brasileña para indagar sobre su carta antepasada. Boulus estaba desconcertado por la falta de atención de la embajada. En su segunda carta, Boulus proporcionó al personal de la embajada aún más detalles sobre la situación de los hijos del señor Ali. En su segundo intento, Boulus minimizó el carácter malicioso de Ali que se exhibió en la primera carta. En esta ocasión informó a las autoridades brasileñas que Ali estaba muy enfermo y que, en su opinión, pronto moriría. "Si la situación financiera del padre lo hubiera permitido", escribió, "podría haber arreglado la repatriación de los niños el mismo"58. Sin embargo, según Boulus, Ali había perdido toda su fortuna inmobiliaria de la que había dependido para su regreso a Brasil. Boulus volvió a centrar su atención en la situación de los niños y explicó que "estos jóvenes brasileños" vivían sin ningún apoyo financiero no solo por la enfermedad de Ali, sino también porque "no pueden ganarse la vida" ya que no hablan árabe ${ }^{59}$. Anticipando que no recibiría respuesta de la embajada, Boulus comunicó que, si la situación de los niños Ali carecía de méritos a los ojos del consulado, entonces el trataría por cuenta propia de "sacarlos de este estancamiento" 60 .

El 29 de mayo de 1933, Boulus recibió una carta del cónsul da Costa. En una carta relativamente corta, da Costa intentó explicar la complejidad legal de repatriar a los hijos del señor Ali. Da Costa subrayo que las leyes locales "no reconocían la nacionalidad de los niños solo la del padre, según el "Jus sanguinis""61. El cónsul añadió que "a pesar de su lugar de nacimiento, [los niños eran] considerado sirio y, en cualquier caso, aún bajo la precedencia legal del 'patrio poder""62. También informó a Boulus que había explicado verbalmente a los dos jóvenes que, de conformidad con las leyes locales, en referencia a la ley islámica, dado que Ali era musulmán y en ausencia del padre, "las costumbres locales y las leyes confieren amplios derechos al hijo primogénito" 63 . "Si [el padre] renuncia a este derecho", agregó, "corresponde a las autoridades locales, quienes deben decidir y tienen el deber de resolver esta

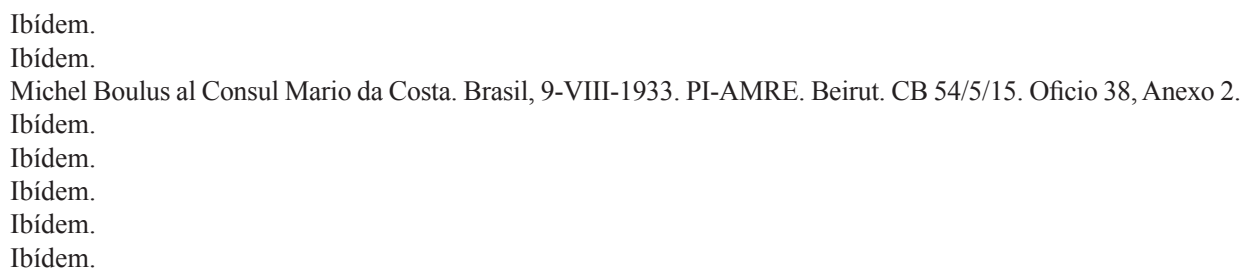


cuestión y la protección de los menores" ${ }^{\text {. }}$. Por lo tanto, el joven musulmán debería de desafiar la autoridad del padre enfermo. Esta era la única solución para sus problemas y los de sus hermanos y hermanas. Al hacerlo, se dejaría que las autoridades locales, nacionales e internacionales decidieran o negociaran su ciudadanía legítima $\mathrm{y}$ de tomar las medidas apropiadas.

El joven Mamed Ali estaba decidido a escapar de la situación incierta que enfrentaban él y sus hermanos y trató de obtener el apoyo de las autoridades consulares aprovechando su sentido de nacionalismo, patriotismo y la hermandad brasileña que todos teóricamente compartían. En una carta a da Costa, Mamed resumió los eventos y las circunstancias que llevaron a su familia a Siria, así como las razones de su deseo de regresar, junto con sus hermanos, a Brasil. El joven explicó que su padre había nacido en Siria. Cuando era joven, su padre inmigró al estado de Bahía, Brasil, donde conoció y consecutivamente contrajo nupcias con su madre, una mujer brasileña, natural de aquel estado. Después de varios años, tuvieron cinco hijos, de los cuales el joven Mamed era el mayor con 17 años. Un día, su padre decidió regresar a su tierra natal y se trajo con él a los cuatro hijos mayores, dejando el infante de escasos tres años en cargo de su esposa. Mamed explicó que antes de la Primera Guerra Mundial, su padre había enviado 800 libras esterlinas a su familia en Siria. Infelizmente, al terminar la guerra toda su familia había muerto y junto con ellos su fortuna monetaria. Al llegar a Siria se encontró en una situación de gran desespero, sin familia, sin dinero, y sin recurso ni para encontrar empleo. Por estos motivos, su padre se rindió a sus penas, y de un día para otro, el señor despertó con el cuerpo físicamente paralizado. Los cuatro hijos con la ayuda de diferentes vecinos árabes ingresaron al padre en un hospital. Al quedar el padre hospitalizado, los hermanos terminaron sin madre, sin padre, sin parientes, sin dinero y sin recursos para sobrevivir, en una tierra extranjera sin el conocimiento del idioma para trabajar. “¿Estamos en una situación muy terrible! Algunos días comemos, otros no sabemos qué es eso" 65 .

Al encontrarse en tales circunstancias, el joven Mamed entró en contacto con el embajador brasileño, "represéntate de [su] Patria querida"66. La primera vez que el joven Mamed entabló contacto con la embajada fue con la ayuda del señor Ahmad Ali. El señor Ali era el barbero del pueblo quien al sentir perna por los jóvenes sacrificó su tiempo y dinero para llevar a los dos hermanos a Beirut. Él gastó una fortuna en trasporte, comida y alojamiento. Desafortunadamente, en aquella ocasión, el cónsul da Costa les informó que él no contaba con los medios para repatriarlos, "que no tenía ni el dinero ni la orden legal para hacerlo"67. Pero al no darse por vencido, el joven Mamed, en una nueva ocasión, suplicó al cónsul que solicitará autorización al presidente de los Estados Unidos de Brasil, "quien representa el jefe supremo de esa noble nación brasileña", la necesaria ayuda para repatriarlo y a sus hermanos. Mamed señaló que la repatriación a Brasil habilitaría a todos los hermanos a servir a su querido país, Brasil, mucho mejor allá que "aquí en un país extranjero"68. El joven Mamed concluyó su carta explicando que mientras su padre aún gozaba de buena salud le había prometido la mano de su hermana, la menor de diez años, en matrimonio a un hombre de treinta años, cuando ella llegara a la mayoría de edad.

$\begin{array}{ll}{ }^{64} & \text { Ibídem. } \\ { }_{65} & \text { Ibídem. } \\ { }_{6} & \text { Ibídem. } \\ { }_{67} & \text { Ibídem. } \\ { }_{68} & \text { Ibídem. }\end{array}$ 
"Imagínese eso, su excelencia," exclamó el joven, "cuando mi hermana sea mayor de edad, ese hombre cuyo nombre es Mustapha Fayeh, ya será viejo, y yo no aceptaré ese escándalo"69.

En la carta, Mamed Ali, también, expresó su sentido de ser brasileño (brasilidade) al invocar el amor y la lealtad por el único país que reconoció como propio: Brasil. Simultáneamente, rechazó todas las prácticas culturales y religiosas que él consideraba que estaban en oposición a su naturaleza brasileña: árabe, islámico y la propia Siria. Tal vez consciente de los escándalos que involucraron a mujeres brasileñas casadas con hombres musulmanes en el Levante, Mamed, con la ayuda de misioneros cristianos en la región, redactó cuidadosamente su carta con la esperanza de transmitir su propio drama personal. Esto, sin duda, también explotó el creciente sentimiento de nacionalismo e identidad nacional en Brasil. El clima político asociado con el estatus semicolonial de los territorios del mandato francés podría haber influido también en el sentimiento de orgullo nacional de $\mathrm{Mamed}^{70}$. Es imposible saber hasta qué punto la carta influyó en cómo las autoridades brasileñas avanzaron en este caso. Lo cierto es que da Costa parecía haber brindado su apoyo, al menos en la medida de su capacidad como autoridad consular a los niños Ali.

En una carta dirigida a un sacerdote jesuita, el Reverendo Padre Francis Kandela, con fecha de 8 de junio de 1933, da Costa afirmó que conocía la situación de los niños Ali por la correspondencia entre el consulado y el Sr. Boulos. Da Costa compartió la complejidad del caso y enfatizó la política en torno a la naturaleza de la "doble nacionalidad" de los niños ${ }^{71}$. Tomando en consideración la apelación hecha por Mamed Ali, junto con una recomendación escrita del reverendo Kandela, da Costa imploró al sacerdote que ayudara a los niños y que enviará a la embajada los siguientes documentos: prueba de ciudadanía brasileña, como un pasaporte o certificado de nacimiento; el lugar preciso de la residencia de la madre de los niños en Brasil; su situación financiera actual; y una declaración escrita solicitando ayuda del consulado brasileño por el padre de los niños. Da Costa advirtió al sacerdote que "solo después del examen de los documentos solicitados, la embajada podría proporcionar a los niños la ayuda que necesitaban"72. Esta fue una respuesta convencional de las autoridades del consulado en tales circunstancias.

Cuando los hijos de Ali y sus protectores comenzaron la tarea de recopilar los documentos solicitados, se enfrentaron al desafío de obtener la solicitud por escrito del señor Ali. Ali quedó paralizado en una cama de hospital incapaz de hacer uso normal de su cuerpo. Para complicar las cosas, el padre era analfabeto. Los hijos de Ali contactaron a la embajada para pedir orientación sobre cómo resolver esta solicitud casi imposible. En una carta a la embajada, los niños de Ali notificaron a las autoridades que era "completamente imposible" 73 que su padre enviara a la embajada una declaración escrita en la que solicitaba ayuda de las autoridades brasileñas. Citando el hecho de que su padre era analfabeto, pero incluso si no fuera, recalcó

Mamede Ally Jr. al Consul Mario da Costa. Brasil, 9-VIII-1933. PI-AMRE. Beirut. CB 55/1/1. Oficio 38, Anexo 5. Consul Mario da Costa al Rev. P. Francis Kandela S. J. Brasil, 9-VIII-1933. PI-AMRE. Beirut. CB 54/5/15. Oficio 38, Anexo 6, 9 de agosto de 1933.

Ibídem.

Ibídem.

Mamede Ally Jr. - Miguel Ally - Waldelice Ally - Olinda Ally al Consul Mario da Costa. Brasil, 9-VIIII-1933. PI-AMRE. Beirut. CB 54/5/15. Oficio 38, Anexo 8, 9 de agosto de 1933. 
Memed, "él no podría escribir porque su mano no proporciona el movimiento normal y, actualmente, incluso cuando yo (Mamed) escribo esta [carta], continúa en la misma condición física"74.

Las autoridades de la embajada aconsejaron a los niños que insistieran a que el señor Boulus pasara por el hospital y, después de explicarle el procedimiento a Ali, "redactar una declaración autenticada y corroborada por un testigo adecuado"75. Esta maniobra legal abrió la posibilidad de una repatriación sin problemas para los niños. Sin embargo, el padre, incluso en su lamentable condición, parecía estar en contra de la repatriación de su hija menor, Olinda ${ }^{76}$. El señor Ali continuó percibiendo a su hija menor potencialmente útil para su futura estabilidad económica, al quererla casar no sólo la vendía como a un objeto, sino también la condenaba a un cautiverio eterno.

Después de muchas negociaciones locales, nacionales e internacionales en las que participaron el consulado brasileño en Beirut, el Ministerio de Relaciones Exteriores en Río de Janeiro y la oficina del Haut-Commissaire de la Republic Française (Alto Comisionado Francés), la saga de los niños parecía llegar a su fin. El 15 de septiembre de 1933, da Costa informó al ministro del Estado de Relaciones Exteriores que el 5 de septiembre el Alto Comisionado Francés había proporcionado al consulado la declaración del padre de Ali solicitando que el consulado interviniera en la repatriación de sus cuatro hijos ${ }^{77}$. El 11 de julio de 1934, quince meses después de la solicitud inicial de Boulus, el consulado brasileño notificó a las autoridades de Río de Janeiro que los niños se dirigían a Brasil para reunirse con su madre y su hermano menor $^{78}$.

En los siguientes años las repatriaciones de niños menores de edad y algunos otros indigentes concurrió con mucha más facilidad. Tal fue el caso del joven Mauricio Zehuri y sus cuatro hermanos que fueron repatriados por las autoridades consulares el día 27 de noviembre de $1934^{79}$. De la misma manera fueron repatriados la familia de Pedro Léon Bassi1 ${ }^{80}$, Antônio Abrão Zainum ${ }^{81}$ y del joven Aristides Namour ${ }^{82}$. En este último caso, el joven Namour llegó a acompañado de su padre a la ciudad de Homs, Siria, en 1931. Por ser menor de edad, su padre lo obligó a acompañarlo. Sin embargo, por su condición de menor, su padre adquirió un permiso del Juez de Menores, en la ciudad de São Paulo, donde el señor Zaki Namour se comprometía a repatriar a su hijo cuando cumpliera la mayoría de edad ${ }^{83}$. Dos años después, el señor Namour regresó a Brasil dejando al joven Aristides en la ciudad de Homs. Fue en abril de 1935, al cumplir la mayoría de edad que el joven Namour pidió la asistencia de las autoridades consulares para forzar a su padre a que lo repatriara a Brasil o que le mandara una cantidad mayor de dinero para sobrevivir en Siria ${ }^{84}$. Desafortunadamente para el joven Aristides, su padre había fallecido escasos días atrás, el 19

\footnotetext{
Ibídem.

Consul Mario da Costa al Rev. P. Francis Kandela S. J. Brasil, 9-VIII-1933. PI-AMRE. Beirut. CB 54/5/15. Oficio 38, Anexo 6, 9 de agosto de 1933.

76 Ibídem.

77 Repatriação de Mamde Ally Jr. e Irmãos. Brasil, 15-IX-1933. PI-AMRE. Beirut. CB 54/5/15. Oficio 45.

78 Indice dos Officios Expedidos em 1934. Brasil, 2II-1935. PI-AMRE. Beirut. CB 54/5/15. Oficio 12, Anexo 1.

79 Repatriação Filhos Abrahim Zehuri. Brasil, 5-XII-1934. PI-AMRE. Beirut. CB 54/5/15. Oficio 61.

80 Repatriação Familia Pedro Léon Bassil. Brasil, 27-III-1935. PI-AMRE. Beirut. CB 54/5/15. Oficio 22.

81 Repatriação de Antonio Abrão Zainun. Brasil, 19-II-1935. PI-AMRE. Beirut. CB 54/5/15. Oficio 17.

82 Repatriação de Aristides Namour. Brasil, 26-XII-1935. PI-AMRE. Beirut. CB 54/5/15. Oficio 51.

83 Ibídem.

84 Ibídem.
} 
de abril, y la posibilidad de repatriarlo caía en las manos de su madre ${ }^{85}$. Cuando las autoridades encontraron a la viuda Namour, ella expresó su alegría a la posibilidad de tener a su hijo Aristides de vuelta con ella. Pero las circunstancias económicas en las cuales se encontraba la viuda, teniendo que sustentar a sus diez hijos menores, ahora sin la ayuda de su esposo, la imposibilitaban para ayudar económicamente a la repatriación de su querido hijo ${ }^{86}$. Teniendo en cuenta la tragedia familiar de los Namour, el gobierno decidió repatriar al joven Aristides el 23 de julio de $1935^{87}$.

\section{4. "Peut-on Être Libanais et Brésilien?"\$8}

El largo proceso de repatriación de los niños Ali, aunque fue una victoria moral para las partes involucradas, no proporcionó soluciones concretas al creciente número de ciudadanos brasileños que buscaban asistencia del consulado en Beirut. El consulado enfrentó dos obstáculos importantes. El primero fue la falta de fondos inmediatos para pagar los costos de transporte asociados con la repatriación de ciudadanos brasileños. El segundo, como lo ilustra la situación con los niños Ali, tenía que ver con los principios legales que definían el estado de ciudadanía en relación con los hijos de padres sirio-libaneses. En una carta fechada en 9 de agosto de 1933, dirigida al ministro del Estado, Afranio de Mello Franco, da Costa informó al ministro sobre el creciente número de casos legales relacionados con el tema de la doble ciudadanía. Da Costa explicó que las leyes de Brasil, Líbano y Siria sobre este problema legal, en particular, a menudo estaban en desacuerdo. La ley siria basó su ciudadanía en la rúbrica de "Jus sanguinis", mientras que la ley brasileña la basó en el "Jus solis"89. De acuerdo con H. S. Q. Henriques, la adopción de una ciudadanía basada en el país de nacimiento facilita el control del estado sobre la misma ciudadanía porque el estado puede verificar la documentación de nacimiento y cuando la ciudadanía se pierde o se cambia. Mientras que la nacionalidad basada en las líneas familiares puede ignorar la nacionalidad del padre o madre, o si en algún momento alguno de ellos perdió su nacionalidad. El no tener una nacionalidad o el tener doublé nacionalidad, Henriques lo clasifico como dos "grandes males" para la fundación de las leyes de nacionalidad $^{90}$. Mientras la comunidad mundial continúe favoreciendo un sistema de ciudadanías basado en jus sanguinis o jus soli, los que enfrentarán demandas conflictivas, de alómenos dos estados, serán aquellos individuos escudriñados por ambos partes de este sistema dividido ${ }^{91}$. El caso de los niños Ali sirvió para ejemplificar otros casos similares que involucraron a la embajada brasileña. Debido a la incompatibilidad de las leyes, este tipo de casos, de acuerdo con el cónsul da Costa, "se vuelven difíciles de resolver a la luz de los derechos paternos y las circunstancias

\footnotetext{
85 Consul H. Sully de Souza al Chefe do Gabinete de Investigações. Brasil, 26-XII-19365. PI-AMRE. Beirut. CB 54/5/15. Oficio 51, anexo 1 .

86 Ibídem.

87 Repatriação de Aristides Namour. Brasil, 26-XII-1935. PI-AMRE. Beirut. CB 54/5/15. Oficio 51.

88 Recorte de jornal sobre nacionalidade. Brasil, 8-II-1935. PI-AMRE. Beirut. CB 54/5/15. Oficio 15, Anexo 1.

89 Consul Mario da Costa a Rev. P. Francis Kandela S.J. Brasil, 9-VII-1933. PI-AMRE. Beirut. CB 54/5/15. Oficio 38, Anexo 9, 1. Ciudadanía determinada de acuerdo con la ciudadanía de los padres. Véase Scott, 1930; Henriques - Schuster, 1917; Cook-Martín, 2013.

90 Henriques - Schuster, 1917.

91 Cook-Martín, 2013: 3.
} 
bajo las cuales se encontraron las partes interesadas, ya que su segunda madre patria les debe la misma asistencia" 92 .

Aproximadamente un año y medio después del intercambio entre da Costa y de Mello Franco, el periódico en lengua francesa, L'Orient publicó un artículo titulado "Peut-on Etre Libanais et Brésilien?" ". El artículo informaba acerca de un debate público sobre derecho internacional privado celebrado en el Tribunal Mixte. Este debate fue presidido por el señor Arène, una autoridad en el tema. El artículo investigó el caso de un inmigrante libanés llamado Cyprianos que regresó al Líbano "hábilmente" con dos "état-civils" diferentes que fueron legalmente adquiridos: un pasaporte brasileño y un documento de identidad libanesa, ambos auténticos y váli$\operatorname{dos}^{94}$. Dependiendo de las circunstancias que afrontaba Cyprianos, de acuerdo con el artículo, él invocaba una nacionalidad u otra. El artículo acusaba que el estatus legal de Cyprianos beneficiaba convenientemente a sus maniobras "insensibles" como litigante en asuntos legales, al tiempo que proporcionaba una posición desfavorable para sus oponentes legales ${ }^{95}$. La Sra. Germanos, una abogada que, argumentando en contra de esta práctica, instigó un debate más amplio sobre el tema. Cuando pidió a Cyprianos que seleccionara una nacionalidad permanente, el señor Dorlac, un abogado experto en cuestiones de doble ciudadanía intervino e indicó el siguiente punto jurídico:

Independientemente de la nacionalidad extranjera que Cyprianos deseaba seleccionar, aquí, para ser reconocido por las autoridades libanesas, primero este debe haber cumplido las condiciones y los desafíos básicos de una autorización especial del gobierno libanés - juez supremo - para conferir el poder a las personas que salen del país, al adoptar cualquier nacionalidad que no sea la suya ${ }^{96}$.

Las observaciones del Sr. Dorlac apuntaban a las leyes de naturalización acatadas por Siria y Líbano después de su institución política como estado-nación independientes de un desaparecido Imperio Otomano, de acurdo con el Tratado de Lausana. El artículo concluyó señalando que la opinión expresada por Dorlac hacía eco de las condiciones aplicadas durante la época otomana. Bajo la ley otomana, según el artículo, "cualquier antiguo súbdito otomano al ser readmitido en la tierra imperial primero tenía que obtener un decreto o îra especial del sultán. De lo contrario, en los ojos de las autoridades otomanas, él continuaba siendo un súbdito de su majestad imperial" ${ }^{\prime 97}$. El legado de las leyes coloniales otomanas reflejadas en las leyes de los gobiernos sirio y libanés, en el parecer del gobierno brasileño, evocaban un sentimiento de atraso y una legislación incivilizada, una percepción relacionada con el pasado islámico no-blanco europeo del Levante.

La cuestión de la doble ciudadanía, el de poder ser simultáneamente brasileño y libanes o sirio, rápidamente desapareció de los debates públicos porque se oponía al proyecto internacional de la construcción del estado, dado este nuevo orden mun-

\footnotetext{
92 Consul Mario da Costa a Rev. P. Francis Kandela S.J. Brasil, 9-VII-1933. PI-AMRE. Beirut. CB 54/5/15. Oficio 38, Anexo 9, 2. PI-AMRE. Beirut. CB 54/5/15. Oficio 38, Anexo 2, 9 de agosto de 1933, p. 2.

93 Recorte de jornal sobre nacionalidade. Brasil, 8-II-1935. PI-AMRE. Beirut. CB 54/5/15. Oficio 15, Anexo 1.

94 Ibídem.

95 Ibídem.

96 Ibídem.

97 Ibídem.
} 
dial, los gobiernos de Brasil, Líbano, Siria, y Francia trabajaron conjuntamente para deshilar las complejidades de identidad política de las almas bajo su control o protección. Para incapacitar el número de ciudadanos brasileños viviendo indefinidamente fuera de territorio nacional, el gobierno brasileño promulgo el decreto de ley n. ${ }^{\circ} 389$, del 25 de abril de 1938. El artículo 27 de tal ley consideró que habían renunciado a la nacionalidad brasileña o naturalizada, quienes residieran durante más de dos años consecutivos en su país de origen o de nacionalidad anterior, o aquellos que residieran por cinco años consecutivos fuera de Brasil, a menos que demostraran, dentro de tales los plazos, que pretendían regresar a Brasil, y que su residencia en el extranjero se debía simplemente a razones de salud relevantes, por negocios con firmas brasileñas, por representación oficial de alguna institución religiosa, científica, o filantrópica, o al servicio del gobierno ${ }^{98}$.

Esta nueva ley forzó a los brasileños viviendo en Siria y Líbano a confrontar de una manera dinámica sus deberes de ciudadanía o definitivamente renunciar a ella. A la nueva ley se le añadía las interacciones de ciudadanos con estatus políticos "cuestionables" a los cuales se les inspeccionaba rutinariamente bajo la mirada fija de los tres estados políticos para esclarecer o negocias sus identidades nacionales. En el caso del señor Hassib Gabara, el gobierno libanés protestó el estatus de ciudadano brasileño que él ejercía durante su estadía en el Líbano ${ }^{99}$. De acuerdo con un reporte del consulado brasileño, el gobierno libanés por medio del Alto Comisionado Francés pedía el esclarecimiento de como tal ciudadano obtuvo la ciudadanía brasileña. De acuerdo con el reporte, el señor Gabara residía en el Líbano desde el 30 de agosto de 1924, un año después de adoptarse el tratado de Lausana (julio de 1923), cual bajo su artículo 30, todo libanés requería la autorización de ese gobierno para poder adquirir la ciudadanía de cualquier otro país, inclusive Brasil. Mientras que el señor Gabara poseía su documento de identidad brasileña, por el hecho de nunca haber cumplido, mientras vivió en el Líbano, "con sus deberes como ciudadano brasileño", y con la aplicación de la ley n ${ }^{\circ} 389$, del 25 de abril de 1938 , es muy probable que el señor Gabaran perdió su ciudadanía brasileña ${ }^{100}$.

En otro caso similar, el Alto Comisionado de Francia intervino en nombre del gobierno libanés para esclarecer la ciudadanía del señor Arifi Hatum, nacido en la ciudad de Kfarselwan, Líbano ${ }^{101}$. De acuerdo con el gobierno libanés, el señor Hatum era legalmente un ciudadano libanés. Después de una investigación basada en la documentación de identidad política del señor Hatum, que de la misma manera que el señor Gabara nunca se había presentado al consulado brasileño en Beirut, las autoridades consulares pudieron demostrar que el señor Hatum poseía un pasaporte brasileño emitido por la Policía Civil de Rio de Janeiro el 19 de junio de $1935^{102}$. El pasaporte del señor Hatun, a diferencia del documento de identidad en posesión del señor Gabara, el pasaporte de Hatum tuvo el poder de determinar sin ninguna duda que el señor Hatum era ciudadano brasileño.

En el caso del señor Wadih Fares Achkar, la cuestión de la ciudadanía ilustra como las estructuras de la familia para tomar decisiones de la identidad colectiva familiar tienen, en algunos casos, repercusiones en la identidad política individual. El señor

\footnotetext{
98 Brasil, 1945: 199.

99 Naturalização de Hassib Gabara. Brasil, 8-IV-1940. PI-AMRE. Beirut. CB 54/1/4. Oficio 37.

100 Ibídem.

101 Naturalização de Arifi Hatum. Brasil, 9-IV-1940. PI-AMRE. Beirut. CB 54/1/4. Oficio 38.

102 Ibídem.
} 
Achkar, director de la compañía Sociedade Brasil-Oriente de Expansão Comercial $L t d$., Líbano, se encontraba en el Líbano promoviendo la venta y promoción de café nacional en el Medio Oriente, y otros países ${ }^{103}$. En una carta escrita por el señor Achkar dirigida al cónsul da Costa, Achkar le explicó que en el día 16 de mayo de 1940, se dirigió a la oficina de Seguridad Publica para obtener un permiso de viaje para la ciudad de Port Said en Egipto. Al tramitar su pedido, la fuerza pública lo detuvo expresándole que su ciudadanía brasileña había sido anulada "por una decisión de la Comisión de Nacionalidades del Alto Comisionado Francés" ${ }^{104}$. La decisión de aquella comisión fue basada en el artículo 34 del Tratado de Lausana, artículo que otorgaba la opción para todos los antiguos súbditos otomanos de nacionalizarse como ciudadanos libaneses o sirios. De acuerdo con la investigación conducida por el consulado, el señor Achkar optó "espontáneamente por la nacionalidad de sus padres" el día 5 de mayo de 1926 en el consulado francés en la ciudad de São Paulo, Brasil ${ }^{105}$. En virtud de ese esa opción, en los ojos del Estado libanés, el señor Achkar había renunciado legalmente a su ciudadanía brasileña y adquirido la libanesa. Fue por ese lamentable acto de comunión familiar que el señor Achkar imploró a las autoridades del consulado brasileño que "intervinieran oficialmente ante las autoridades competentes" para ayudarlo a preservar "su nacionalidad legitima"106 Aunque el señor Achkar presento como evidencia de su ciudadanía su acta de nacimiento y pasaporte brasileños, en la opinión de los agentes consulares, la ciudadanía brasileña solo podía "restablecerse en Brasil"107.

Aquellos instruidos en los nuevos reglamentos para la retención de la ciudadanía brasileña se presentaban ante las autoridades consulares para pedir una prolongación de su permanencia en Siria o Líbano de acuerdo con la ley. El señor Manoel Elias, naturalizado brasileño, acudió al consulado para pedir la prolongación de su estadía en el Líbano, por un año más, citando motivos de salud según el certificado médico que presentó a las autoridades ${ }^{108}$. En la correspondencia con el Ministerio de Relaciones Exteriores en Rio de Janeiro, con fecha de 13 de abril de 1940, el cónsul da Costa indicó que el ciudadano Elias se había registrado en esa sede el día 2 de febrero de 1932. Elias estaba casado con una mujer extranjera con la cual tenía un hijo nacido en Brasil y otros cuatro nacidos en el Líbano, ninguno de los menores estaba registrado en el consulado ${ }^{109}$. El cónsul también le indicó el ministro que el señor Elias estaba en plena disputa legal sobre algunos terrenos locales y que era costumbre de estos ciudadanos, como el caso anterior del el señor Cyprianos, utilizar el Consulado General "para proteger sus intereses con las autoridades locales y los Tribunales Mixtos de su país de origen" ${ }^{110}$. En el caso de José Chamon, también naturalizado, pidió una extensión por dos años por razones comerciales el 18 de noviembre de $1939^{111}$. El señor Chamon era comerciante establecido en Beirut traba-

103 Nacionalidade do Sr. Wadih Fares Achkar. Brasil, 24-VI-1940. PI-AMRE. Beirut. CB 54/1/4. Oficio 71.

104 Commission Des Nationalites a Wadih Fares. Brasil, 24-VII-1940. PI-AMRE. Beirut. CB 54/1/4. Oficio 71.

105 Ibídem.

106 Wadih Fares Achkar al Consul Mario da Costa. Brasil, 24-VII-1940. PI-AMRE. Beirut. CB 54/1/4. Oficio 71, 24 de junio de 1940, anexo 3.

107 Nacionalidade do Sr. Wadih Fares Achkar. Brasil, 24-VI-1940. PI-AMRE. Beirut. CB 54/1/4. Oficio 71.

108 Prorogação de estadia no país de origem do brasileiro naturalizado Manoel Elias. Brasil, 15-III-1940. PIAMRE. Beirut. CB 54/1/4. Oficio 40.

109 Ibídem.

110 Ibídem.

111 Prorogação de estadia no país de origem do brasileiro naturalizado José Chamon. Brasil, 1-IV-1940. PI-AMRE. Beirut. CB 54/1/4. Oficio 41. 
jando para la compañía Suter, Baumann \& Co., quien representaba los intereses de varias compañías brasileñas de alto comercio. Su expediente también indico que estaba casado con una extranjera y tenía cuatro hijos, los cuales no estaban registrados en el consulado. En estos dos casos, es prudente indicar que en cuanto los dos ciudadanos utilizaron el consulado para extender su estancia para preservar su ciudadanía brasileña, al no registrar a sus hijos como ciudadanos brasileños ponían en peligro la posibilidad de que sus hijos menores, al alcanzar su mayoría de edad, adoptaran una ciudadanía que tal vez no era la que ellos hubieran escogido. De esta manera prolongando la cuestión de ciudadanía entre esto posibles ciudadanos brasileños.

Finalmente, el ciudadano brasileño Miguel Dau se presentó en abril de 1940 en la embajada brasileña para solicitar una extensión de estadía en el Líbano por razones de salud. El naturalizado brasileño regresó, a su país de nacimiento, para vivir algunos años. Al llegar al Líbano, el ciudadano acudió a la embajada el 31 de enero de 1931, para matricularse como brasileño viviendo en ese país. De acuerdo con las informaciones del consulado, el señor Dau era soltero con 68 años y a diferencia de sus conciudadanos, el señor Dau visitaba la embajada cada año para regularizar su estadía en el Líbano sin poner en peligro su título de nacionalidad ${ }^{112}$. Después de revisar y verificar los documentos requeridos para tomar una decisión sobre la petición del señor Dau, los agentes del Ministerio de las Relaciones Exteriores se comunicaron con el cónsul da Costa señalándole que el certificado de naturalización proveído por el señor Dau no constaba con una fecha de emisión ${ }^{113}$. Al mismo respecto, los agentes le pidieron, al cónsul, que les explicara cómo había basado su "decisión de considerar al Señor Miguel Dau un ciudadano naturalizado"114. En respuesta a esas preguntas, el cónsul indico que el señor Dau había presentado su título de elector y pasaporte, ambos documentos adquiridos o certificados en Brasil, aparte de su título de naturalización y al estar registrado en el consulado de Brasil en Beirut. Consecuentemente el cónsul explicó que la razón por la cual el certificado de naturalización no presentaba una fecha de emisión exacta era porque la nacionalidad del señor Dau "fue establecida por el Decreto n ${ }^{\circ}$ 58-A del 14 de diciembre de 1889"115. El cónsul concluyo su respuesta a las autoridades en Rio subrayando que aparte del certificado de naturalización, los otros documentos presentados por el señor Dau eran equivalentes y demostrativos de su ciudadanía brasileña de acuerdo con el artículo 2 de la ley no 904 del 12 de enero de 1902.

\section{Conclusión}

Desde su llegada a Brasil, los inmigrantes otomanos se encontraron en un país que no los acogió abiertamente, clasificándolos como indeseables. La proclamación de la Primera República cambió la trayectoria de vida para muchos de estos inmigrantes al proporcionarles la oportunidad de naturalizarse ciudadanos brasileños y de adquirir una clasificación de ciudadanos blancos en una sociedad racialmente estratificada

112 Prorogação de estadia no país de origem do brasileiro naturalizado Miguel Dau. Brasil, 16-IV-1940. PI-AMRE. Beirut. CB 54/1/4. Oficio 42.

113 Prorogação de estadia no país de origem do brasileiro naturalizado Khalil João Jacob. Brasil, 27-IV-1940. PIAMRE. Beirut. CB 54/1/4. Oficio 48.

114 Ibídem.

115 Ibídem. 
donde los blancos se posicionaban en un lugar de privilegio social. Por primera vez en su historia, estos hombres y mujeres comenzaron a entenderse como ciudadanos y no como súbditos, un proceso que compartieron no solamente con otros inmigrantes europeos, pero también con la ciudadanía brasileña: todos juntos aprendieron a hacerse brasileños.

En los años de 1930s, muchos ciudadanos natos y naturalizados volvieron a sus tierras ancestrales, o a las de sus padres, de Siria y Líbano por motivos diferentes. Para algunos de ellos, la ciudadanía brasileña les proporcionó una protección en cuestiones legales, principalmente en defensa de sus intereses económicos. Para otros, esto significó la posibilidad de recibir ayuda del gobierno para poder regresar a Brasil después de encontrarse en un estado de indigencia. Para la mayoría de los ciudadanos brasileños menores de edad, las leyes brasileñas, sirias, libanesas, y francesas obstaculizaban el proceso de repatriación que en aquellos tiempos suscitaba un sentimiento de doble ciudadanía. La idea de una doble ciudadanía enfrentó el poder de los cuatro estados que se movilizaron a promulgar leyes para definir el limbo legal en el cual muchos ciudadanos o residentes, en este caso brasileños, se encontraban.

Estas leyes llevaron a las autoridades brasileñas a proteger y ayudar principalmente a mujeres y niños brasileños que vivían en esa región a regresar a su "verdadera" patria civilizada. Sin embargo, los brasileños sirio-libaneses que vivían en Siria o en el Líbano tuvieron que defender la visión racializada del estado brasileño hacia el pueblo del Medio Oriente y su historia. Un proceso en el cual los sirio-libaneses brasileños tuvieron que rechazar una parte de sí mismos, como por ejemplo aquellos de fe musulmana. Esto fue el precio a pagar para conservar sus privilegios de ciudadanos blancos en una nación supuestamente civilizada en la cual el color definió, desde sus principios, la ciudadanía le su población. No obstante, estas leyes también movilizaron a los ciudadanos brasileños, en Siria y Líbano, a tomar conciencia del significado de ser brasileño (brasilidade) en el Levante y ejecutar de manera activa sus deberes de ciudadanos brasileños. Estos procesos transnacionales influyeron en el significado de ser brasileño más allá del mar Atlántico.

\section{Referencias bibliográficas}

Abdeluahed, Akmir (coord.). Los árabes en América Latina: historias de una emigración. Madrid: Siglo XXI de España-Biblioteca de la Casa Árabe, 2009.

Andrews, George Reid. Blacks and Whites in São Paulo Brazil 1888-1988. Madison: University of Wisconsin Press, 1991.

Bento, Maria Aparecida Silva. "Branqueamento e branquitude no Brasil". En Psicologia social do racism - estudos sobre branquitude e branqueamento no Brasil, coordinado por Carone, Iray - Bento, Maria Aparecida Silva - Carone, Iray. Petrópolis, RJ: Editora Vozes, 2002.

Berridge, G.R. "Diplomatic Integration with Europe before Selim III". En Ottoman Diplomacy Conventional or Unconventional?, editado por Yurdusev, A. Nuri. New York: Palgrave Macmillan, 2004.

Brasil. Constituição da Republica dos Estados Unidos do Brazil Acompanhada das Leis Orgânicas Publicadas desde 15 de Novembro de 1889. Rio de Janeiro: Imprensa Nacional, 1891.

Brasil. Relatório do Ministério das Relações Exteriores Relativo ao Ano de 1939. Rio de Janeiro: Impresa nacional, 1945. 
Camil, Renato. Anthropometria ou methodo para verificação de identidade pessoal. Rio de Janeiro: Typographia do "Jornal do Commerico" de Rogrigues \& Comp., 1898.

Campos, Mintaha Alcuri. Turco pobre, sírio remediado, libanês rico: a trajetória do imigrante libanês no Espírito Santo (1910-1940). Vitória, ES: Instituto Jones dos Santos Neves, 1987.

Conrad, Robert Edgar. The Destruction of Brazilian Slavery, 1850-1888, 2ª edición. Malabar, FL: Krieger Publishing Company, 1993 [1972].

- World of Sorrow: The African Slave Trade in Brazil. Baton Rouge and London: Louisiana State University Press, 1986.

Cook-Martín, David. The Scramble for Citizens: Dual nationality and State competition for Immigrants. Stanford, CA: Stanford University Press, 2013.

Cortês, Geraldo de Menezes. Migração e colonização no Brasil. Rio de Janeiro: Livraria J. Olympio Editôra, 1958.

Chalhoub, Sidney. Trabalho, lar e botequim: o cotidiano dos trabalhadores no Rio de Janeiro da belle époque. Campinas, SP: Editora da Unicamp, 2001.

Dávila, Jerry. "Ethnicity, identity and nationality in Latin America". Jewish History, vol. 18, $\mathrm{n}^{\mathrm{o}} 1$ (2004), 95-113.

Domingues, Petrônio. Uma história não contada: negro, racismo e branqueamento em São Paulo. São Paulo: SENAC, 2004.

Duoun, T.A. A imigração sírio-libanesa às terras da promissão. São Paulo: Tipografia Editora Árabe, 1944.

Earle, Rebecca. The Body of the Conquistador: Food, Race and the Colonial Experience in Spanish America, 1492-1700. Cambridge: Cambridge University Press, 2012.

Fausto, Boris. Crime e cotidiano: a criminalidade em São Paulo 1880-1924. São Paulo: Editora Brasiliense, 1984.

- (org). Fazer a América: a imigração em massa para América Latina, $2^{\text {nd }}$ ed. São Paulo: Editora da Universidade de São Paulo, 2000.

FitzGerald, David Scott - Cook-Martín, David. Culling the Masses: The Democratic Origins of Racism Immigration Policy in the Americas. Cambridge, MA: Harvard University Press, 2014.

Gattaz, André Castanheira. Do Libano ao Brasl: história oral de imigrantes. São Paulo: Gandalf, 2005.

Greiber, Betty Loeb - Saigh Maluf, Lina - Cattini Mattar, Vera. Memórias da imigração: libaneses e sírios em São Paulo. São Paulo: Discurso Editorial, 1998.

Gualtieri, Sarah. Between Arab and White: Race and Ethnicity in the early Syrian American Diaspora. Berkeley: University of California Press, 2009.

Hajjar, Claude Fahd. Imigração árabe: cem anos de reflexão. São Paulo: Icone Editora, 1985.

Henriques, H. S. Q. - Schuster, Ernest J. “'Jus Soli' or 'Jus Sanguinis'?”. Problems of the War, vol. 3 (1917), 119-131.

Hormeyer, Joseph. O Rio Grande do Sul de 1850: descrição da província do Rio Grande do Sul no Brasil meridional. Porto Alegre, RS: D.C. Luzzatto Editores: EDUNISUL, 1986.

Hutter, Lucy M. Imigração italiana em São Paulo de 1902 a 1914: o processo imigratório. São Paulo: Instituto de Estudos Brasileiros, Universidade de São Paulo, 1986.

Karam, John Tofik, Another Arabesque: Syrian-Lebanese Ethnicity in Neoliberal Brazil. Philadelphia: Temple University Press, 2007.

Khatlab, Roberto. Brasil-Líbano: amizade que desafia a distância. Bauru, São Paulo: EDUSC, 1999.

Knowlton, Clark S. "Spatial and Social Mobility of the Syrian and Lebanese in the city of São Paulo". Tesis Doctoral, Vanderbilt University, 1955. 
Kircuoglu, Omer. “The Adoption and use of Permanent Diplomacy". En Ottoman Diplomacy Conventional or Unconventional? editado por Yurdusev, A. Nuri. New York: Palgrave Macmillan, 2004, 131-150.

Kutlu, Mehmet Necati. "Reflexiones sobre el inicio de las relaciones otomano-brasileñas". En Imperio Otomano-América Latina (Periodo Inicial), editado por Kutlu, Mehmet Necati - Atakan, Sebnem - Yurtaydin, Erkan - Kaygusuz, Ozlem - Cicek, Nazan - Erdem, Gokhan. Ankara: Publicaciones del Centro de Estudios Latinoamericanos, 2012, 29-62.

Lesser, Jeffrey. Negotiating National Identity: Immigrants, Minorities, and the Struggle for Ethnicity in Brazil. Durham: Duke University Press, 1999.

Lewis, Bernard. From Babel to Dragomans: Interpreting the Middle East. Oxford: Oxford University Press, 2004.

Lew-Williams, Beth. The Chinese Must Go: Violence, Exclusion, and the Making of the Alien in America. Cambridge, MA: Harvard University Press, 2018.

López, Ian Haney. White by Law: The Legal Construction of Race. New York: New York University Press, 1996.

Loveman, Mara. National Colors: Racial Classification and the State in Latin America. Oxford University Press, 2014.

Mendoça, Joseli Nunes. Cenas da abolição: escravos e senhores no parlamento e na justicia. São Paulo: Editora Fundação, 2001.

Morrill, Justin S. Immigration Abuses: Remarks of Justin S. Morrill of Vermont, in the Senate of the United States, December 14, 1887, on Bill (S. 141) to Regular Immigration and other Purposes. Washington, D. C.: United States Government, 1887.

Osman, Samira Adel. Imigração Árabe no Brasil: histórias de vida de libaneses muçulmanos e cristãos. São Paulo: Xamã, 2011.

Pinto, Paulo Gabriel Hilu da Rocha. Árabes no Rio de Janeiro: Uma Identidade Plural. Rio de Janeiro: Cidade Viva, 2010.

Railton, Ben. The Chinese Exclusion Act: What it Can Teach Us about America. New York: Palgrave Macmillan, 2013.

Sáfady, Jamil. “A imigração árabe do Brasil”. Tesis Doctoral, Universidade de São Paulo, 1972.

Scott, James Brown. "Nationality: Jus Soli or Jus Sanguinis". American Journal of International Law, vol 24, $\mathrm{n}^{\circ} 1$ (enero 1930), 58-64.

Skidmore, Thomas E. Black into White: Race and Nationality in Brazilian Thought. Durham: Duke University Press, 1993.

Sochaczewski, Monique. Do Rio de Janeiro a Instanbul: contrastes e conexões entre o Brasil e o Império Otomano (1850-1919). Brasília: Fundação Getúlio Vargas, 2017.

Soennichsen, John. The Chinese Exclusion Act of 1882. Santa Barbara, CA: Greenwood, 2011.

Truzzi, Oswaldo. Sírios e libaneses: a alavancagem pelo comércio. São Carlos, SP: Departamento de Ciências Sociais, Universidade Federal de São Carlos, 1993.

— "Sírios e libaneses em São Paulo: a anatomia de sobre-represenação". En Imigração e Política em São Paulo, editado por Fausto, Boris - Grun, Roberto - Sakurai, Célia - Truzzi, Oswaldo. São Paulo, Brazil: Editora Sumaré, 1995, 27-70.

— "The Right Place at the Right Time: Syrians and Lebanese in Brazil and the United States, A Comparative Approach". Journal of American Ethnic History vol. 16, nº 2 (Invierno, 1997a), 3-43.

- Patricios: sírios e libaneses em São Paulo. São Paulo, HUCITEC, 1997 b. 
— "Sírios e libaneses e seus descendentes na sociedade Paulista". En Fazer a América: a imigração em massa para América Latina, organizado por Fausto, Boris, 2a edición. São Paulo: Editora da Universidade de São Paulo, 2000, 315-352.

— "Religiosidade Cristã entre Árabes em São Paulo: Desafios no Passado e no Presente". Religião e Sociedade, vol. 36, nº 2 (2016), 266-291. 